\title{
A Case Study of Concrete Pavement Deterioration by Alkali-Silica Reaction in Korea
}

\author{
Seung-Ho Hong ${ }^{1)}$, Seung-Hwan Han ${ }^{2)}$, and Kyong-Ku Yun ${ }^{3) *}$
}

(Received May 7, 2007, Accepted October 24, 2007)

\begin{abstract}
The concrete pavement of the Seohae Highway in Korea has suffered from serious distress, only four to seven years after construction. Deterioration due to Alkali-Silica Reaction (ASR) has seldom been reported per se in Korea, because the aggregate used for the cement concrete has been considered safe against alkali-silica reaction so far. The purpose of this study is to examine the deterioration caused by an alkali-silica reaction of concrete pavement in Korea. The investigation methods included visual inspection and Automatic Road Analyzer (ARAN) analysis of surface cracks, coring for internal cracks, stereo microscopic analysis, scanning electronic microscope (SEM) analysis, and electron dispersive X-ray spectrometer (EDX) analysis. The results are presented as follows: the crack pattern of the concrete pavement in Korea was longitudinal cracking, map cracking or D-cracking. Local areas of damage were noticed four to five years after construction. The cracks started from edges or joints and spread out to slabs. The most intensive cracking was observed at the intersection of the transverse and longitudinal joints. Where cracking was the most intense, pieces of concrete and aggregate had spalled away from top surface and joint interface area. The progress of deterioration was very fast. The reaction product of alkali-silica gel was clearly identified by its generally colorless, white, or very pale yellow hue seen through a stereo optical microscopy. The typical locations of the reaction product were at the interface between aggregate and cement paste in a shape of a rim, within aggregate particles in the cracks, and in the large void in the cement paste. Most of the white products were found at interface or internal aggregates. SEM and EDX analysis confirmed that the white gel was a typical reaction product of ASR. The ASR gel in Korea mainly consisted of Silicate (Si) and Potassium (K) from the cement. The crack in the concrete pavement was caused by ASR. It seems that Korea is no longer safe from alkali-silica reaction.
\end{abstract}

Keywords: alkali-silica reaction, ASR gel, cracking and spalling, concrete pavement, Korea

\section{Introduction}

Alkali-silica reaction (ASR) occurs in concrete when alkalis from the cement or from an external source react with free silica present in certain aggregates to form an alkali-silica gel. The alkali-silica gel has the propensity of taking in water and expanding. This expansion can cause the aggregate particles and the concrete to crack and ultimately can damage the concrete pavements. ${ }^{1}$ Concrete pavements stay wet for a long period of time and, thus, are treated with sodium chloride as a de-icing measure during winter. They are, therefore, in the high-risk category of ASR as defined by the Cement and Concrete Association of England. ${ }^{1}$

Alkali-silica reaction first became an emerging issue in California in the USA during the 1930s, when cracking and expansion

\footnotetext{
${ }^{1)} \mathrm{KCI}$ member, Pavement Research Group Highway \& Transportation Technology Institute Korea Highway Corporation Hwasung 445-812, Korea.

${ }^{2)}$ KCI member, Pavement Research Group Highway \& Transportation Technology Institute Korea Highway Corporation Hwasung 445-812, Korea.

${ }^{3)} \mathrm{KCI}$ member, Dept of Civil Engineering Kangwon National University Chuncheon, 200-701, Korea E-mail:kkyun@kangwon.ac.kr

Copyright (c) 2007, Korea Concrete Institute. All rights reserved, including the making of copies without the written permission of the copyright proprietors.
}

of structural concrete in bridges, pavements, and sea wall were investigated. $^{2}$ Instances of alkali-silica reaction have been reported from England, Denmark, Germany, Canada, New Zealand, India, Japan, China, and other countries since then. Deterioration due to ASR has seldom been reported per se in Korea because the aggregate used for the cement concrete has been considered safe against alkali-silica reaction. However, the distresses due to ASR in a concrete pavement section, which showed typical cracking and spalling patterns of ASR, were reported in Korea in 2004. Thus, Korea is considered no longer safe from alkalisilica reaction.

The purpose of this study is to investigate and identify the deterioration caused by alkali-silica reaction of concrete pavement in Korea. The investigation methods included visual inspection and ARAN analysis of surface cracks, coring for internal cracks, stereo microscopic analysis, scanning electronic microscope (SEM) analysis, and electron dispersive X-ray spectrometer $(\mathrm{EDX})$ analysis.

\section{Cases of concrete pavement deterioration in Korea}

Recently, an increasing number of deteriorated concrete pavements have been observed in Korea. The main distress types are cracking, 
spalling, scaling, delamination and pop-outs. These deteriorations were premature distresses because they occurred only four to seven years after construction. The concrete pavement at Seohae Highway in Korea has suffered from serious distress in a short span of time. Over several years, these areas had been identified mistakenly as ordinary distress caused by a combination of reasons not including the alkali-silica reaction.

Seohae Highway was the first site in Korea, at which the deterioration was identified as being caused by ASR. The highway has three lanes in each direction; each lane is $3.7 \mathrm{~m}$ in width. There is a $6 \mathrm{~m}$ long joint space in the concrete pavement. The transverse joints were doweled by round steel bars of $32 \mathrm{~mm}$ diameter spaced by $450 \mathrm{~mm}$ at the first lane and $300 \mathrm{~mm}$ at the second and the third lanes, and the longitudinal joints were tied by rebars of $16 \mathrm{~mm}$ diameter spaced by $750 \mathrm{~mm}$ along the longitudinal joints. The first and the second lanes were paved at the same time, and the third lane was separately paved due to the constraint of pavers. ${ }^{3}$

\subsection{Case1: seven-year-old concrete pavement}

A section of jointed plain concrete pavement (JPCP), located from 282 to $285 \mathrm{~km}$ of Seohae Highway southbound, was constructed in 1996. Seven years had passed by 2004, reaching only one-third of its design life. If local areas of damage were noticed four to five years after construction, they were repaired with patches of bituminous mortar. In cases where the damage was too severe, it was cut out to $60 \mathrm{~mm}$ in depth and then overlaid by asphalt mixtures.

The first row of Table 1 shows the in situ concrete mix proportion, which had been used for the pavement construction of Case 1 . The cement was the Ordinary Portland Cement, and the mixture had unit cement content of $345 \mathrm{~kg} / \mathrm{m}^{3}$. The coarse aggregate was a crushed one with $32 \mathrm{~mm}$ maximum size from Hwasung, and the fine aggregate was sea-dredged natural sand from Hwasung and Pyungtaek, in Korea. The sea-dredged natural sand was washed and processed to the requirement of KS Specification. ${ }^{4}$

\subsection{Case 2: four-year-old concrete pavement}

The jointed concrete pavement of Case 2, located from 199 to $205 \mathrm{~km}$ of Seohae Highway southbound, was constructed in 2001. Local areas of damage began to be observed only two years after construction.

The second row of Table 1 shows the in situ concrete mix proportion used for the pavement construction of Case 2. The cement was the Ordinary Portland Cement. The coarse aggregate was a crushed, black shale with $32 \mathrm{~mm}$ maximum size from Seosan, and the fine aggregate was sea-dredged natural sand from the west coast of Korea.

\section{Evaluation of deteriorations caused by alkali-silica reaction}

\subsection{Visual inspection and image analysis of the pavement surface}

The concrete pavement of Case 1 and Case 2 on Seohae Highway was visually inspected, as illustrated in Fig. 1. Cracks were found distinctively at the third lane of Case 1 and the first and second lanes of Case 2, as shown in Fig. 1(a) and (d), respectively. This development was likely due to the fact that the first and the second lanes of pavement in Case 1 were constructed first and the third lane was paved later due to the aforementioned paver constraint. The cracking patterns were somewhat like longitudinal cracking, map cracking or D-cracking especially observed at the joint.

Figure 1(a) shows the longitudinal cracking; the orientation of predominant cracks on transversely crossed jointed pavement was longitudinal. The cracking pattern certainly showed that more prominent cracks occurred in the longitudinal direction of the pavement. This cracking pattern developed uniformly across the width of the pavement in general, although cracks in wheel paths were more apparent due to the infiltration of dirt and crumbling of crack edges to create apparently greater width.

Map or random cracking has no predominant orientation, meaning the various cracks show no strongly preferred direction. Severe map cracking brought about spalling at joints or pop-out at the surface, and a white deposit or gel was visible as depicted in Fig. 1(b). The width of cracks varied widely while the widest cracks were usually visible on some edges of the pavement. White deposit was observed, which will be further evaluated to identify its chemical composition.

The cracks started from edges or joints and spread out to slabs. The most intensive cracking occurred at the intersection of the transverse and longitudinal joints. Where cracking was most intense, pieces of concrete and aggregate had spalled away from the top surface and the joint interface area. The pattern and location of the cracking was of so-called "D-cracking", named after the shape of the cracked area. Cracking pattern resembling D-cracking was more severe or appeared initially along joints. Cracking along the joint was usually perpendicular to the joint and was associated with a fainter map-cracking as shown in Fig. 1(c). D-cracking was caused by ASR or freeze-thaw damage or both.

AASHTO $^{5}$ provides patterns of cracking due to ASR in concrete pavement as a guide for a rapid identification of alkali-silica reaction products in concrete. Sakar et al. ${ }^{6}$ also provide cracking pattern near the joint of the pavement. Comparing the results of this study with those of AASHTO $^{5}$ and Sakar ${ }^{6}$ may confirm the crack pattern in Korea is of that cracking.

Table 1 In situ concrete mix proportions.

\begin{tabular}{|c|c|c|c|c|c|c|c|c|c|c|}
\hline \multirow{2}{*}{ Case } & \multirow{2}{*}{$\begin{array}{l}\text { Target flexural strength } \\
(\mathrm{MPa})\end{array}$} & \multirow{2}{*}{$\mathrm{W} / \mathrm{C}^{1)}$} & \multirow{2}{*}{$\mathrm{S} / \mathrm{A}^{2)}$} & \multirow{2}{*}{$\begin{array}{c}\text { Air content } \\
(\%)\end{array}$} & \multirow{2}{*}{$\begin{array}{l}\text { Slump } \\
(\mathrm{mm})\end{array}$} & \multicolumn{5}{|c|}{ Unit weight $\left(\mathrm{kg} / \mathrm{m}^{3}\right)$} \\
\hline & & & & & & Cement & Water & Fine sgg. & Coarse agg. & $\mathrm{AE}^{3)}(\%)$ \\
\hline Case 1 & 4.5 & 0.44 & 0.4 & 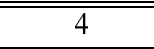 & 40 & 345 & 152 & 734 & 1,139 & 0.15 \\
\hline Case 2 & 4.5 & 0.444 & 0.39 & 4 & 25 & 338 & 150 & 713 & 1,133 & 0.3 \\
\hline Spec. & 4.5 & 0.423 & 0.38 & 4 & 40 & 340 & 144 & 678 & 1,162 & 0.1 \\
\hline
\end{tabular}

1) water-cement ratio

2) fine aggregate ratio

3) air-entraining agent $(\%)$ 


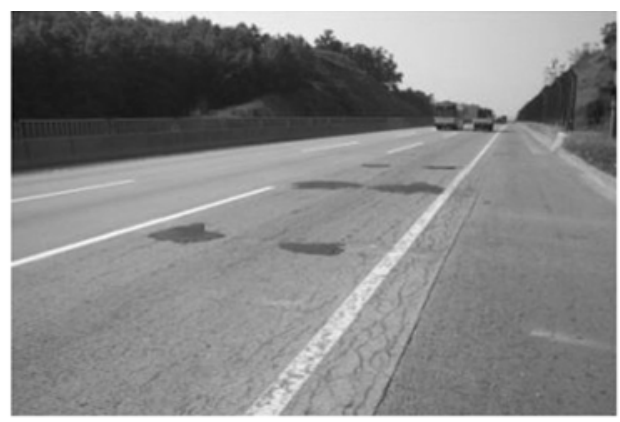

(a) Random cracking at $3^{\text {rd }}$ lane of case 1

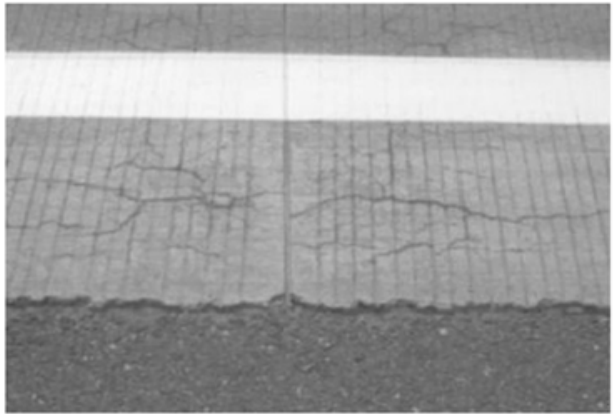

(c) Random cracking at 1 st lane of case 2

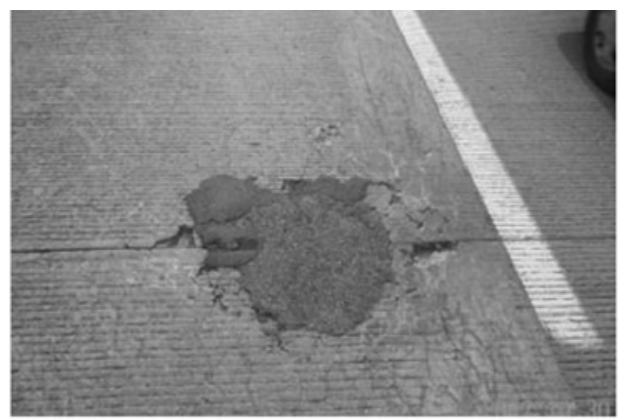

(b) Cracking and spalling at $2^{\text {nd }}$ lane of case 1

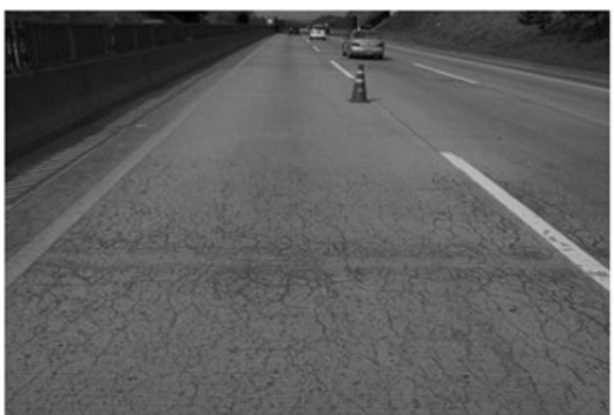

(d) Cracking at 1 st and $2^{\text {nd }}$ lane of case 2

Fig. 1 Surface cracking and spalling in the concrete pavement.

An automatic crack inspection was performed by $\mathrm{ARAN}^{7}$. ARAN collected the images of concrete pavement surface conditions in 2002 and 2003 in order to compare the deterioration progress as shown in Fig. 2. The photos show that the pavement had severe random cracking and some portions of the pavement were patched by bituminous mortar. The dotted-line boxes in Fig. 2(a) and (b) indicate the same portion taken in 2002 and 2003, respectively. The patched area enlarged as the deterioration progressed even though it was only one year later. The deterioration was indeed very rapid.

From the result of this visual inspection and ARAN observation, the crack pattern of the analyzed concrete pavement in Korea was determined to be longitudinal cracking, map cracking or D-cracking. The cracked sections were found only in one lane (Case 1) or in two lanes (Case 2) among three lanes of the highway in one direction according to paving conditions. Local areas of damage were noticed four to five years after construction. The cracks started from edges or joints and spread out to slabs. The most intensive cracking was at the intersection of transverse and longitudinal joints. Where cracking was most intense, pieces of concrete and aggregate had spalled away from the top surface and the joint interface area. The progress of deterioration was very rapid.

\subsection{Visual inspection of core}

Cores were taken from severely distressed locations of the pavement in order to investigate the internal distresses, as shown in Fig. 3. It was impossible to test the strength of the cores because of the transverse or vertical cracks developed inside the concrete. The surface crack had vertically progressed from top to bottom as shown in Fig. 3(a). The crack was filled with water to show it clearly. A vertical internal crack occurred through a coarse aggregate as shown in Fig. 3(b). However, several internal horizontal cracks occurred also as shown in Fig. 3(c), and were more predominant than the others. Some of the cracks were so

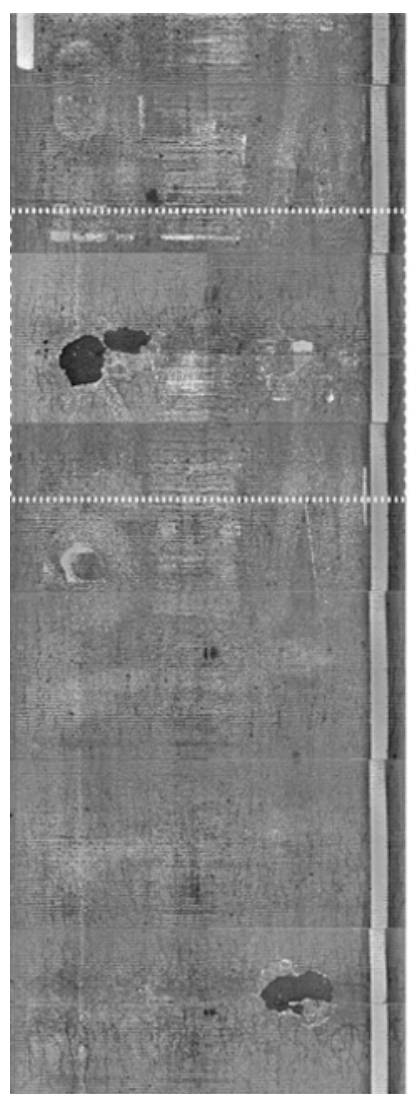

(a) In 2002

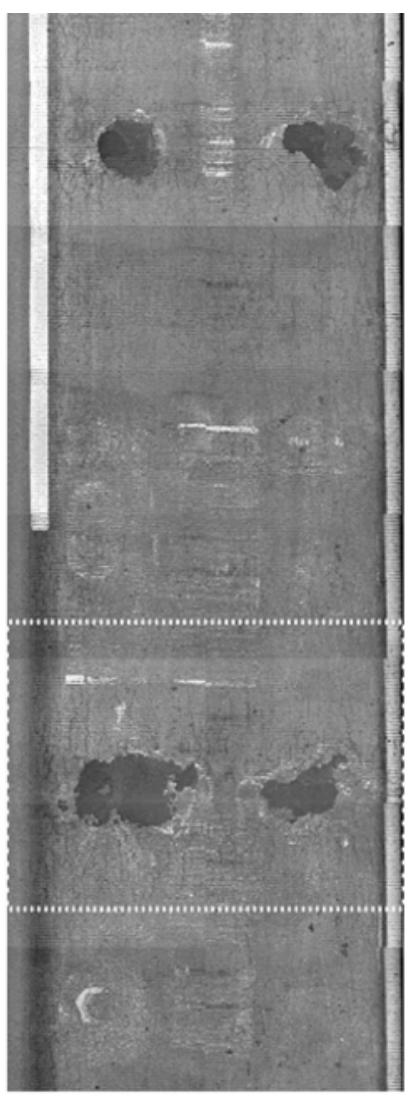

(b) In 2003
Fig. 2 Progress of deterioration in the pavement, images taken by ARAN.

severe that the core was delaminated during coring.

Figure 3(a), which was taken by an ordinary camera, illustrates the rim of white deposit around coarse aggregate. The reaction products were white or colorless, and the product around the aggregate was whitish. The white product could be seen through 


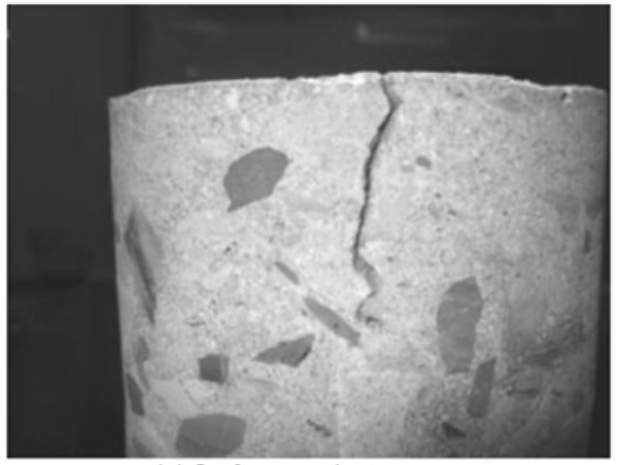

(a) Surface crack at core

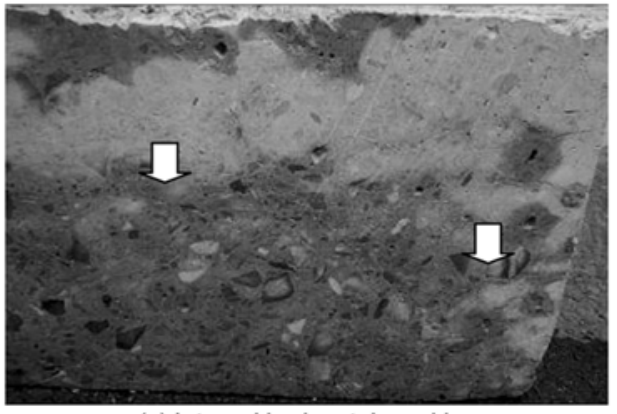

(c) Internal horizontal cracking

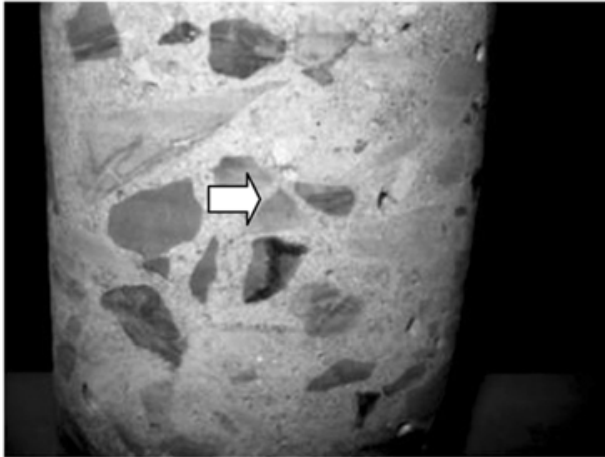

(b) Cracking through aggregate

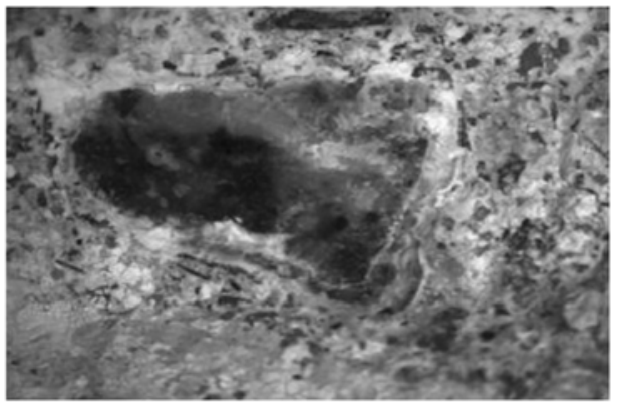

(d) Gel and rim of ASR

Fig. 3 Internal cracks.

simple visual inspection as the water at core surface dried out. Even small aggregate of $3 \mathrm{~mm}$ in diameter could be identified. Some portions of the white product were colorless. Thus, the reaction product of the analyzed pavement in Korea was very similar to a typical alkali-silica gel identifiable even with the naked eye, and the products and crack pattern were the same as those of Farney and Kosmatka. ${ }^{8}$

\subsection{Stereo optical microscopy}

After simple visual inspection and ARAN analysis, the concrete specimens were polished and examined with a stereo optical microscope, the Nikon SMZ 1000, at magnification varying from $10 \mathrm{X}$ to $100 \mathrm{X}$. The magnification was set to $40 \mathrm{X}$ for this analysis. This is a very simple and efficient method for investigating the interface between cement paste and aggregate.

The white alkali-silica gel product was clearly identified by a stereo optical microscopy by its generally colorless, white, or very pale yellow color, as shown in Fig. 4. The typical locations for the gel were at the interface between aggregate and cement paste, as shown in Fig. 4(a), within aggregate particles in the cracks as shown in Fig. 4(b), at and the large voids in the cement paste as shown in Fig. 4(c). Some gels showed cracking at the interface between aggregate and cement interface. Most white products were found at the interface or within internal aggregates.

Microcracking, cracked aggregate particles, and gel-filled microcracks and voids confirmed that an alkali-silica reaction had occurred in the concrete. The reaction product could clearly be differentiated from the cement paste as evidenced by the grey color of the reactive aggregate. Powers ${ }^{9}$ reported that ASR gel filled the interface of aggregate and cement paste and also filled the voids. Adams ${ }^{10}$ reported that ARS gel was formed around the quartzite aggregate as a white rim. Thus, the white product found in this study seems the same as that of ASR reported by FHWA. ${ }^{11}$

\subsection{Scanning electron microscopy (SEM) and energy dispersive X-ray (EDX) analysis}

The scanning electron microscope (SEM) is a type of electron microscope capable of producing high resolution images of a sample surface. Owing to the way the image is created, SEM images are useful in judging the surface structure of the sample. The energy dispersive X-ray (EDX) analysis is a technique used for the identification of the elemental composition of the specimen. The EDX is used in conjunction with SEM for complete investigation and is not a surface science technique. An electron beam strikes the surface of a conducting sample to produce the image.

A HITACHI S-3200N scanning electron microscope and KEVEX sigma MS2 energy dispersive X-ray were used to evaluate the composition of the white gel first identified through visual inspection then confirmed with a stereo microscope.

\subsubsection{Case 1}

The surface of the white product was very smooth, while the cement paste was very rough as shown by the image of the scanning electron micrograph of Fig. 5(a). The white product had many cracks at the surface as shown in Fig. 5(b). Figure 6 compares X-ray spectra of cement paste (a) and reaction product (b). Figure 6(a) shows that the compositions of the cement paste are $\mathrm{Si}^{4+}>\mathrm{Ca}^{2+}>\mathrm{K}^{+}>\mathrm{Al}^{3+}$ in the decreasing order of chemical com-position. The compositions of the cement were very high for silicate $(\mathrm{Si})$ and calcium $(\mathrm{Ca})$, while the white product was mainly composed of potassium (K). These facts indicate that the white product is an ASR gel. Most cement produced in Korea has a high content of potassium $(\mathrm{K})$ and low content of sodium $(\mathrm{Na}){ }^{5}$ thus, ASR might be induced by the high potassium content.

SEM and EDX analysis confirmed the white deposit was a 


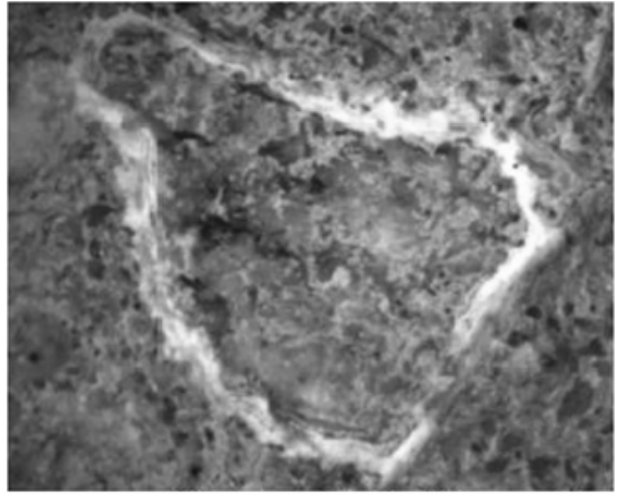

(a) Rim of alkali-silica reaction

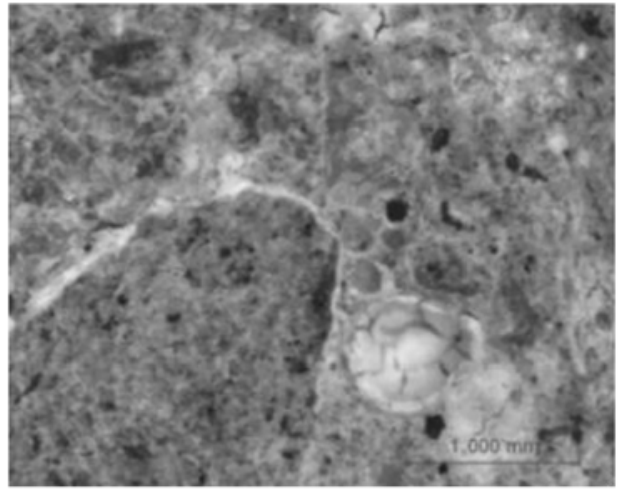

(c) Gel filled in voids

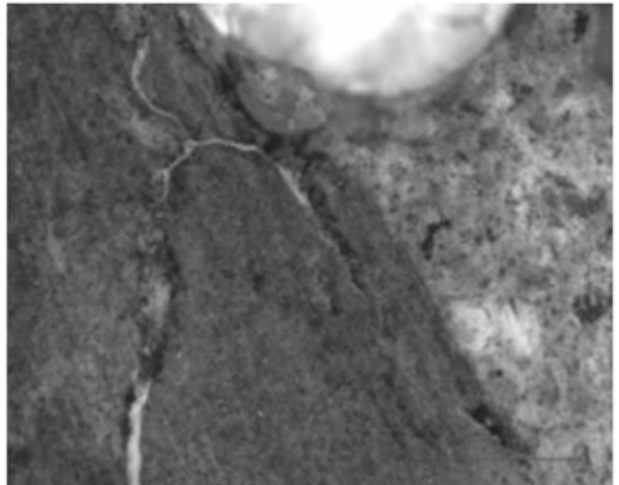

(b) Gel in the crack of aggregate

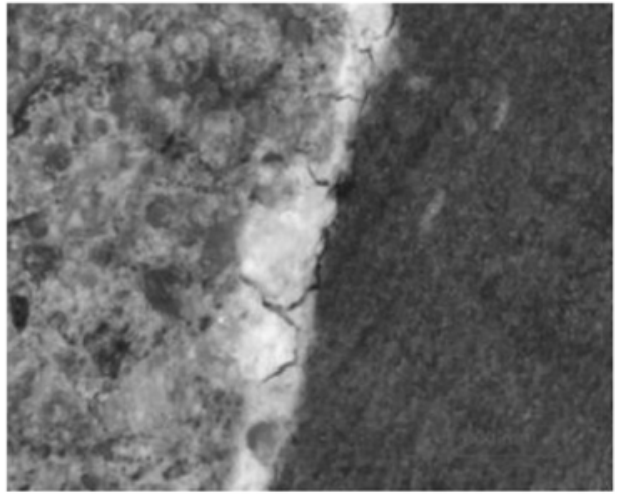

(d) Cracked gel at interface

Fig. 4 Stereo optical micrographs showing white reaction products.

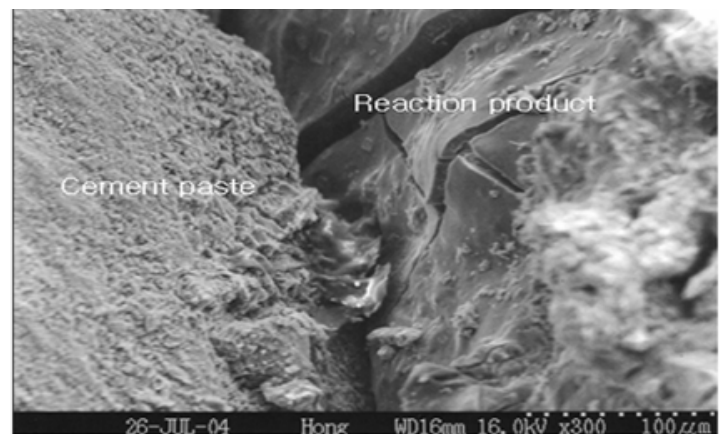

(a) Interface of cement paste and ASR gel

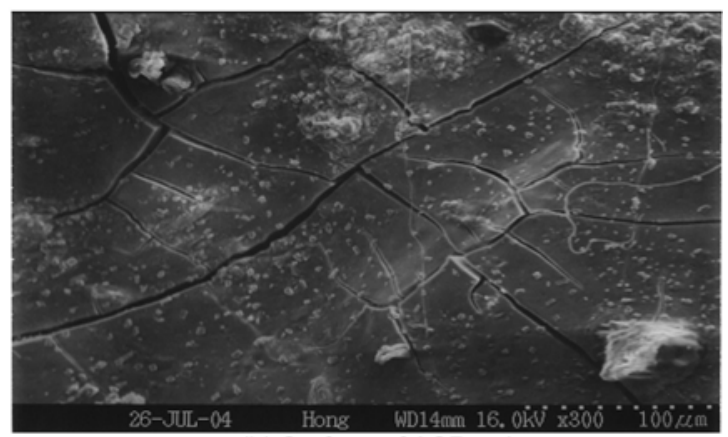

(b) Surface of ASR gel

Fig. 5 Scanning electron micrographs showing ASR gel.

typical reaction product of ASR. The ASR gel of Case 1 mainly consisted of Silicate (Si) and Potassium (K) due to the composition of the cement used in Korea.

\subsubsection{Case 2}

Figure 7(a) presents a SEM image of filled air voids with corres-

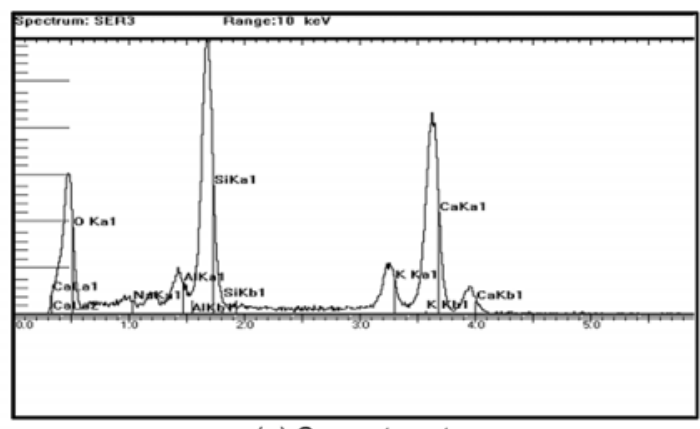

(a) Cement paste

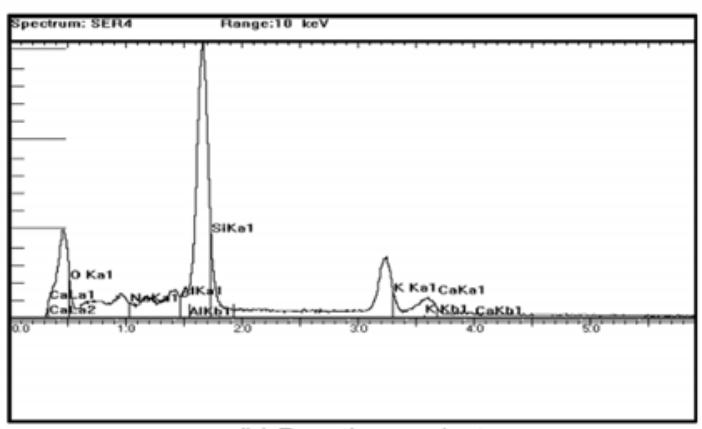

(b) Reaction product

Fig. 6 X-ray spectra.

ponding X-ray spectrum of Fig. 7(b). The EDX analysis shows that the order of chemical composition was $\mathrm{Si}^{4+}>\mathrm{Ca}^{2+}>\mathrm{K}^{+}>$ $\mathrm{Al}^{3+}$, which was a typical composition of ASR gel.

Figure 8(a) presents a SEM image of cement paste near the crack with corresponding X-ray spectra of the aggregate, cracks 
at cement paste, and cement paste only. The orders of chemical composition were $\mathrm{Si}^{4+}>\mathrm{Al}^{3+}>\mathrm{K}^{+}, \mathrm{Ca}^{2+}>\mathrm{Si}^{4+}>\mathrm{K}^{+}>\mathrm{Al}^{3+}$, and

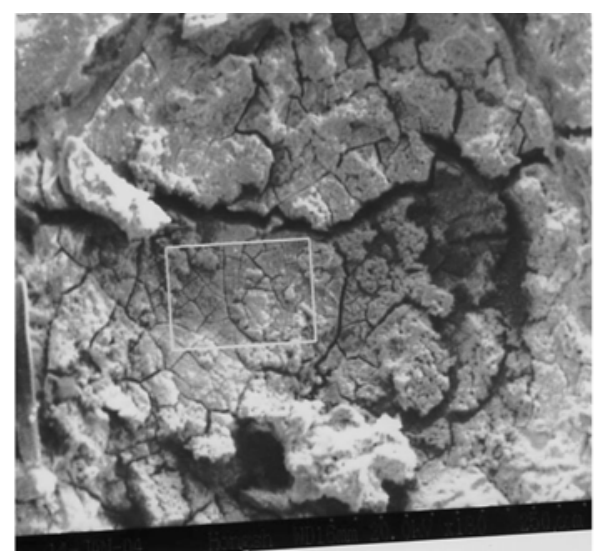

(a) EDX location

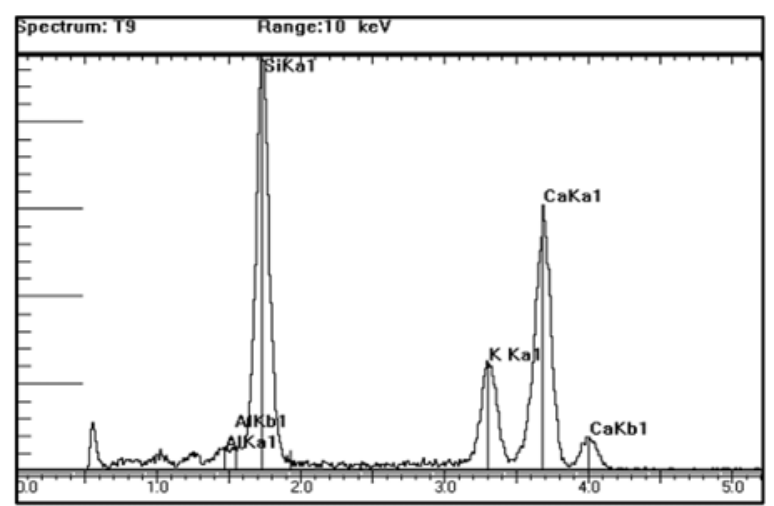

(b) EDX spectrum

Fig. 7 EDX location and spectra of void.

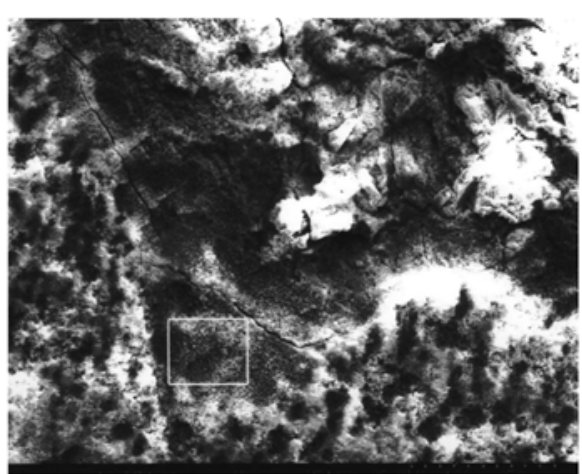

(a) EDX location

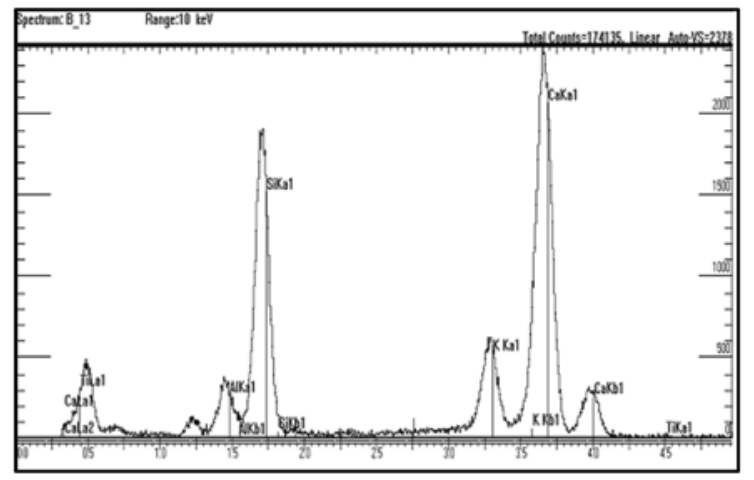

(c) EDX spectrum of crack area
$\mathrm{Ca}^{2+}>\mathrm{Si}^{4+}>\mathrm{Al}^{3+}>\mathrm{K}^{+}$for the aggregate, crack at cement paste, and cement paste, respectively.

Larran̆aga $^{12}$ reported that ASR gel had different chemical compositions depending on the cements and aggregates used, and the order of chemical composition of the ASR gel was $\mathrm{Si}^{4+}>$ $\mathrm{Ca}^{2+}>\mathrm{Na}^{+}$based on an EDX analysis. Cales-Gibergues ${ }^{13}$ also reported that $\mathrm{Si}^{4+}>\mathrm{Ca}^{2+}>\mathrm{K}^{+}$was the order of chemical composition of the ASR gel.

In conclusion, SEM and EDX analysis confirmed the white gel was a typical reaction product of ASR. The ASR gel in Korea mainly consisted of Silicate $(\mathrm{Si})$ and Potassium $(\mathrm{K})$ due to the composition of the cement used in Korea. Previous studies ${ }^{12,13}$ also confirmed the white deposit found in the analyzed cement concrete pavement of Korea was a typical reaction product of ASR, and the crack was induced by the ASR gel. Thus, the crack in the concrete pavement was caused by ASR, and Korea is no longer a zone free from alkali-silica reaction.

\section{Conclusions}

The deterioration of ASR has seldom been reported per se in Korea because the aggregate used for the cement concrete has been considered safe from alkali-silica reaction. However, the distress of ASR in a concrete pavement section was first reported in Korea in 2004. The purpose of this study was to examine the deterioration caused by an alkali-silica reaction of the concrete pavement in Korea. The investigation methods included visual and ARAN inspection for surface cracks, coring for internal cracks, stereo microscopic analysis, scanning electronic microscope analysis, and electron dispersive X-ray spectrometer analysis. The results are as follow:

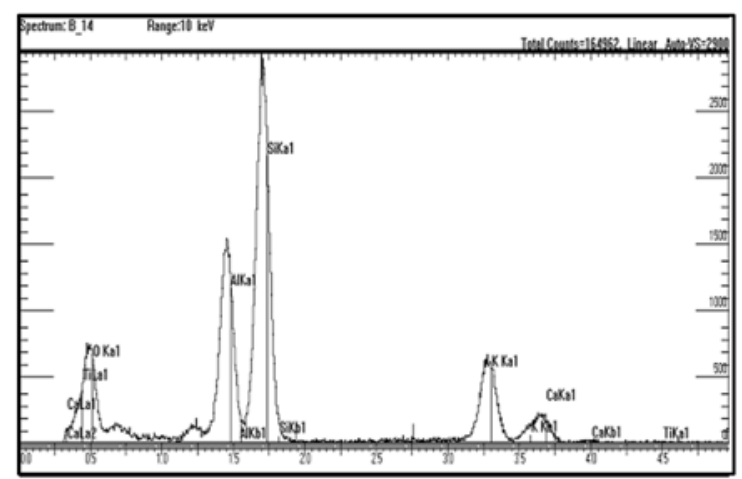

(b) EDX spectrum of aggregate

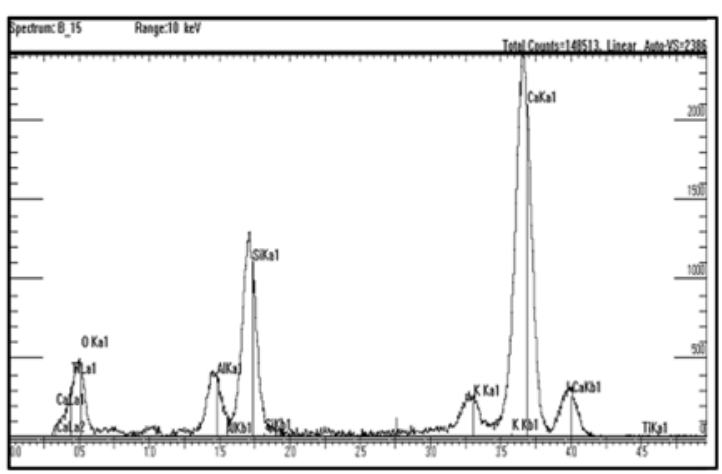

(d) EDX location and spectrum

Fig. 8 EDX location and spectrum. 
1) The crack pattern of the concrete pavement in Korea was longitudinal cracking, map cracking, or D-cracking. Cracking was found only in one or two lanes among three lanes in the same direction as the construction. Local areas of damage were noticed four to five years after construction. The cracks started from edges or joints and spread out to slabs. The most intensive cracking was observed at the intersection of transverse and longitudinal joints. Where cracking was the most intense, pieces of concrete and aggregate had spalled away from the top surface and the joint interface area. The progress of deterioration was very rapid.

2) The reaction product of alkali-silica gel was clearly identified by its generally colorless, white, or very pale yellow hue seen through stereo optical microscopy. The typical locations of the reaction product were at the interface between aggregate and cement paste, within the aggregate particles in the cracks, and in the large voids in the cement paste. Most of the white reaction products were found at the interface or in the internal aggregates. Many previous studies ${ }^{9-11}$ support that the main reaction product of the analyzed concrete pavement in Korea is an ASR gel.

3) SEM and EDX analysis confirmed the white gel was a typical reaction product of ASR. The ASR gel in Korea mainly consisted of Silicate (Si) and Potassium (K) due to the composition of the cement used in Korea. Previous studies ${ }^{12,13}$ also confirmed that the whitish gel formed at cracks in the analyzed concrete pavement in Korea was a typical reaction product of ASR, and that the crack was induced by an ASR gel. Thus, the crack in the concrete pavement was due to ASR. It is deemed that Korea is no longer a zone free from alkali-silica reaction.

\section{References}

1. West, Graham, Alkali-Aggregate Reaction in Concrete Roads and Bridges, Thomas Telford Publications, London, 1996.

2. Stanton, T. E, Expansion of Concrete Through Reaction
Between Cement and Aggregate, Proc., ASCE, Reston, Va., 1940, pp. 1781 1811.

3. Hong, S. H., Investigation and Control of Alkali-Silica Reactivity of Concrete in Korea, Doctoral Dissertation, Kangwon National University, Korea, February, 2006.

4. KS, Ready Mixed Concrete, KS F4009, Korean Standard, Korea, 2001.

5. AASHTO, Rapid Identification of Alkali-Silica Reaction Products in Concrete, AASHTO T299-93, 2002.

6. Sarkar, S. L., Dan G Z., Anal, K. M., Lim, S. W., Handbook for identification of alkali-silica reactivity in airfield pavements, U.S. Department of Transportation, Federal Aviation Administration, AC No150/5380-8 Appendix 1, 2004.

7. Roadware, ARAN (Automatic Road Analyzer) User Mamual, Roadware Co., 1998.

8. Farny, J. A. and Steven H. K., Diagnosis and Control of Alkali-Aggregate Reaction in Concrete, Portland Cement Association, 1997.

9. Powers, L. J., Developments in Alkali-Silica Gel Detection, Concrete Technology Today, April 1999.

10. Adams, N. and David B. S., "Using Advanced Lithium Technology to Combat ASR in Concrete," Concrete International, August 2002.

11. FHWA(Federal Highway Administration), Guidelines for Detection, Analysis, and Treatment of Materials-Related Distress in Concrete Pavement, FHWA Contract DTFH61-96-C-00073, FHWA-RD-01-163, March 2002.

12. Larraňaga, Miren Etxeberria, Experimental Study on Microstructure and Structural Behaviour of Recycled Aggregate Concrete, Doctoral Thesis, Barcelona, March 2004, pp.138 139.

13. Carles-Gibergues, André, Martin Cyr, "Interpretation of Expansion Curves of Concrete Subjected to Accelerated Alkalaggregate Reaction (AAR) Tests," Cement and Concrete Research, Vol.32, 2002, pp.691 700. 